This is an accepted version of the article published in:

Building Acoustics 1-23 (2021).

https://doi.org/10.1177/1351010X211019216

Please cite this document as:

M. Edwards, R. Gonzalez Diaz, N. Dallaji, L. Jaouen, F. Chevillotte, and N. Totaro, "Preliminary rolling noise measurements toward the design of a standard rolling noise device," Building Acoustics, May 2021, DOI: 10.1177/1351010X211019216.

\title{
Preliminary rolling noise measurements towards the design of a standard rolling noise device
}

\author{
M. Edwards ${ }^{* 1}$, R. Gonzalez Diaz ${ }^{2}$, N. Dallaji ${ }^{3}$, L. Jaouen $^{1}$, F. Chevillotte ${ }^{1}$, and N. \\ $\operatorname{Totaro}^{4}$
}

${ }^{1}$ Matelys Research Lab, 7 Rue des Maraîchers, Bât B, 69120 Vaulx-en-Velin, France

${ }^{2}$ Aalto University, Department of Computer Science, P.O. Box 13000, 00076 Aalto, Finland

${ }^{3}$ Moelven Töreboda AB, Bruksgatan 8, 54531 Töreboda, Sweden

${ }^{4}$ INSA-Lyon, 20 Avenue Albert Einstein, 69621 Villeurbanne cedex, France

May 312021

\begin{abstract}
The tapping machine has long existed as the primary standard method for measuring the performance of floors in buildings in response to structure-borne noise. However, other sources of structure-borne noise exist. One of these is rolling noise: such as a trolley rolling across the floor in an indoor building environment. Because the sound profile of indoor rolling noise is substantially different than that of impact noise, the techniques developed to reduce the latter may not necessarily be effective at reducing the former. To this end, a means of repeatably measuring indoor rolling noise is needed. Here the results of a study on indoor rolling noise are presented, identifying the various characteristics of this type of excitation which until now have been left unexplored. The proposal for a standard rolling device is also put forth: a machine which may be capable of characterizing a floor's performance with regards to indoor rolling noise. A series of indoor rolling noise tests were conducted in order to characterize the range of sound profiles that various indoor rolling items are capable of producing, as well as identify how the different characteristics govern the shape of the sound profile produced. Just as the standard tapping machine assesses a floor's performance in response to impact noise, a standard rolling machine may assess a floor's performance in response to rolling noise.
\end{abstract}

*matthew.edwards@matelys.com 


\section{Introduction}

In the field of building acoustics, a standard tapping machine has long existed for the purpose of replicating and regulating impact noise [1]. This device was originally designed to mimic the sound of human footfall [2], and while this is indeed the strongest source of annoyance among survey responders (in regards strictly to floors) [3], there still exist other kinds of structure-borne noise. One of these sources is rolling noise.

Rolling noise is often talked about in regards to outdoor sources such as trains and automobiles, but there are a plethora of indoor rolling sources which can cause annoyance for building inhabitants as well: delivery trolleys in commercial spaces, rolling desk chairs in offices (both personal and commercial), children's toys, and suitcases, for example. As shown in Figure 1, these items generate noise due to the small-scale roughness between the floor and wheels, which causes structure-borne noise to propagate through the building as they roll across the floor.

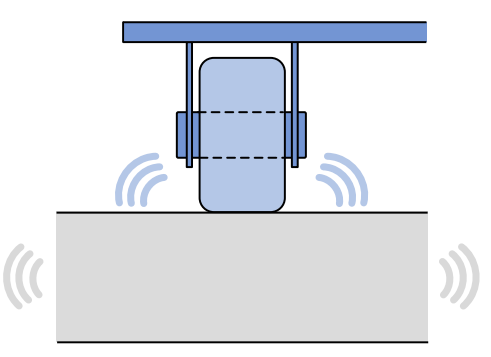

Front view

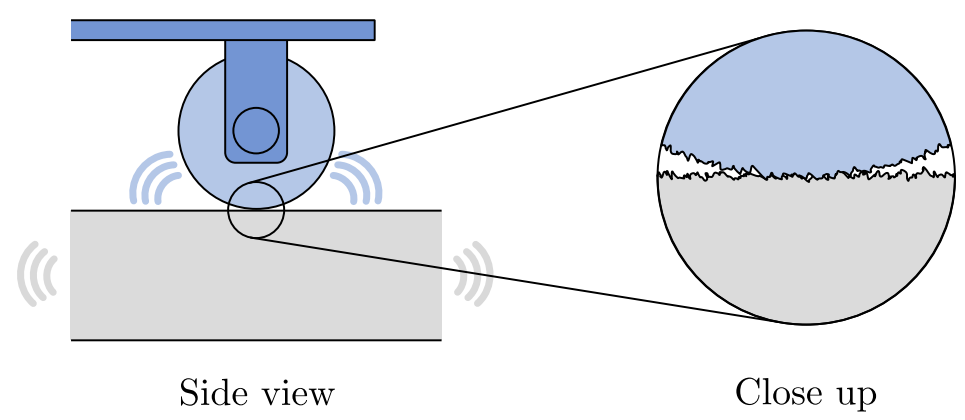

Side view

Close up

Figure 1: A typical rolling noise schematic. The small-scale roughness between the floor and wheel generates structural vibrations as the wheel rolls across the floor.

Sound radiation in buildings is a topic which has been explored previously, but not in the context of rolling noise. Prediction of downward radiation from mechanical excitation exists for sources such as impact noise [4], the rubber ball [1] (see appendix F), walking noise [5], and even rainfall noise [1]. Prediction of upward and lateral radiation from airborne and structure-borne excitation in buildings exists as well [6].

Work on the rainfall excitation of multi-layer systems has been developed by Guigou-Carter et al. [7, 8] and Chéné et al. [9]. In these models (which can be both analytical and numerical), the source is a randomly distributed fixed point excitation. That is, the locations of each raindrop impact are random, but the impact event for a given rain drop is still fixed in space over the short duration of the impact. This is different than impact noise from a tapping machine, which is a single fixed point excitation (i.e. all impacts occur at a single fixed point in space: there is no force distribution $)^{2}$. Both of these however differ from rolling noise, which is a single moving point excitation. The injected force into the floor continuously moves in a line across the floor. Prediction models for indoor rolling noise must be uniquely designed to assess this type of excitation $[10,11,12]$.

Figure 2 shows the normalized sound pressure level $L_{n}$ due to a typical tapping machine and a typical rolling trolley on a classical concrete floor (140 $\mathrm{mm}$ thickness), in addition to the attenuation $\Delta L$ of a classical floating floor $(140 \mathrm{~mm}$ concrete slab + a coupling layer $+40 \mathrm{~mm}$ screed). The normalized sound pressure level is calculated from the measured sound pressure level using

$$
L_{n}=L_{P}+10 \log \left(\frac{A}{A_{0}}\right)
$$

\footnotetext{
${ }^{2}$ Technically the hammer impacts of a tapping machine are distributed as each of the five hammers do not impact exactly the same spot on the floor, but are spaced adjacent to one another. However, they are sufficiently close that compared to other excitation sources, they may be treated as all impacting the same point on the floor.
} 
where $L_{P}$ is the measured sound pressure level in the room, $A_{0}$ is the reference absorption area (equal to $10 \mathrm{~m}^{2}$ for a laboratory), and $A$ is the equivalent absorption area of the room in square meters, calculated via ISO 10140-4 [13].

The attenuation is calculated via ISO 10140-1 [14]

$$
\Delta L=L_{n 0}-L_{n}
$$

where $L_{n 0}$ and $L_{n}$ are the normalized sound pressure levels due to a typical tapping machine on the reference floor (here the classical concrete floor) and the floor under test (here the classical floating floor), respectively.

The spectrum of impact noise is quite different than that of rolling noise. The rolling noise curve exhibits a bell-shaped profile, having the majority of its acoustic energy in the low frequency range. Furthermore, the attenuation of a classical floating floor is inverse to said rolling noise profile. As such, it would not be expected to provide much insulation on its own without additional treatment.

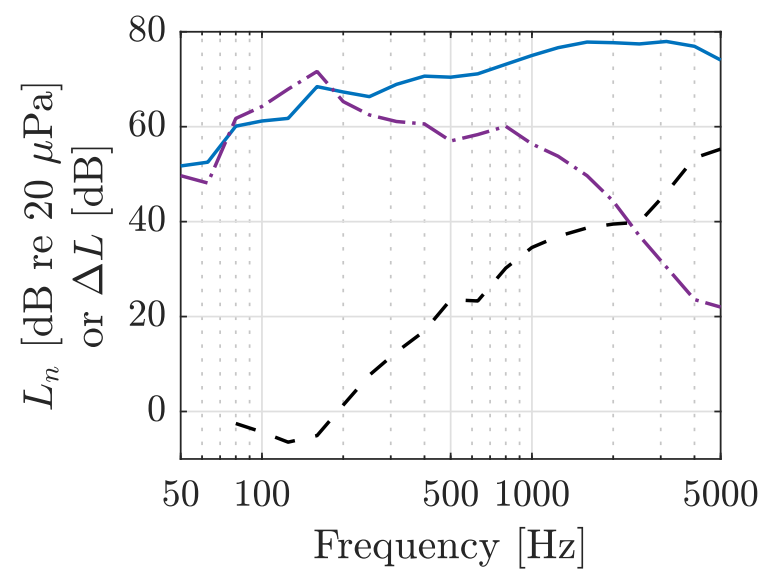

Figure 2: Comparison of the spectra of tapping noise and rolling noise on a classical concrete floor $(140 \mathrm{~mm})$, as well as the attenuation of a classical floating floor (140 $\mathrm{mm}$ concrete slab + a coupling layer $+40 \mathrm{~mm}$ screed). $-L_{n}$ : tapping machine, $-\cdot-\cdot-L_{n}$ : rolling trolley, $--\Delta L$ : attenuation of a classical floating floor.

Other kinds of excitation can generate bell-shaped $L_{n}$ curves, such as rain on the roof or a soft impact. This occurs because the excitation mechanisms inject less energy in the high frequency range [15]. For rolling noise, wavelengths which have dimensions shorter than the contact area between the wheel and floor are naturally filtered out, causing the bell shaped curve seen here. This is known as the contact filter effect. This bell shape shows a connection among various types of rolling sources, not between rolling sources and other kinds of excitation. The physical mechanisms of rain on the roof and/or soft impact excitation are not the same (i.e. no roughness effect).

The difficulty in combating this type of rolling structure-borne noise is that, because its sound signature is starkly different than that of impact noise, the solutions developed to help against impact noise will not necessarily work against rolling noise. Additionally, the modeling techniques which are used in assessing the impact noise in a given environment will not necessarily be able to accurately predict the level of rolling noise in the same environment. A method of generating a standard rolling excitation is needed in order to accurately assess the relative performance of building materials across different locations in response to rolling noise.

A study on the various characteristics of indoor rolling noise is put forth here, as well as a proposal for a standard rolling noise device. Just as the standard tapping machine assesses a floor's performance in response to impact noise, a standard rolling machine may assess a floor's performance in response to rolling noise. To this end, a series of tests were conducted to identify 
the range of sound profiles typically encountered through the use of indoor rolling devices, as well as to identify the various characteristics which play a roll in indoor rolling noise. Conclusions were drawn from the results of these tests in order to guide the development of a standard rolling device design. This work is linked to the recently accepted proposal to the European Committee for Standardization (CEN / TC 126 / WG 7) for a New Work Item: Measurement of rolling sound insulation.

\section{Test location, setup, and procedure}

A series of rolling noise tests were conducted in a two-story transmission room at Level Acoustics \& Vibration in Eindhoven, the Netherlands. The existing standard for the laboratory measurement of impact noise, defined by ISO 10140-3 [4], was adapted here to be used for measuring rolling noise. For each measurement, the device under test was rolled on the test floor in the emission room above for a duration of at least 30 seconds. The sound pressure level, averaged over the entire time span, was measured in the reception room below. A total of five runs were performed and averaged together for each unique configuration in order to eliminate potential variations between runs.

As shown in Figure 3, there was an opening in between the two rooms, inside which a custom floor was installed for testing. This opening, having dimensions of roughly $3 \mathrm{~m} \mathrm{x} 3 \mathrm{~m}$, was filled with a $100 \mathrm{~mm}$ thick isolated concrete slab. The slab was mounted around its perimeter on elastic supports, which decoupled the slab from the surrounding floor structure. This was done to ensure that the sound level in the reception room below was due only to the structure borne noise transferred vertically through the slab when the trolley was rolled in the emission room above. Thus, flanking transfer paths were eliminated.

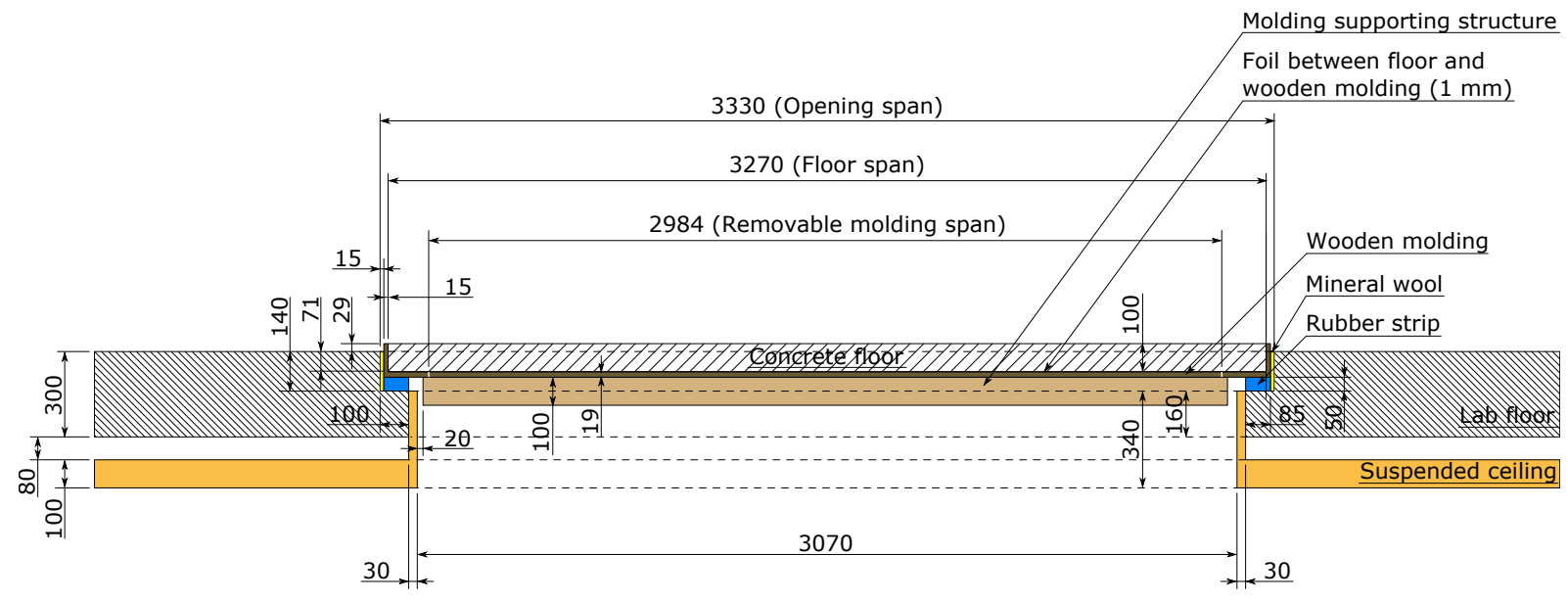

Figure 3: Schematic of the concrete floor installed in the two-story transmission room at Level Acoustics \& Vibration. The wooden molding and molding support structure were only present while pouring the concrete and waiting for it to dry: they were removed prior to testing. All dimensions in millimeters.

Placing the concrete slab on an elastic foundation essentially created a very large spring-massdamper system. The material that was used as the elastic foundation around the perimeter of the slab was chosen such that the structure as a whole had a vertical natural resonance frequency of $10 \mathrm{~Hz}$. This was deemed sufficiently low that excitation by the rolling trolley (acting as a force input to the spring-mass-damper system) would not cause a resonant response.

To ensure there was no contact between the concrete slab and the surrounding floor, a $15 \mathrm{~mm}$ gap was left around the perimeter. This gap was then filled with mineral wool to reduce airborne sound transmission. A transmission loss measurement (conducted via ISO 10140-2 [16] 
and ISO 717-1 [17]) and comparison with the theoretical transmission loss of a $100 \mathrm{~mm}$ concrete slab (computed using Bassist.Lab, an in-house simulation software package developed by Level Acoustics \& Vibration) confirmed that no excess sound was leaking through the slab's elastic foundation and mineral wool perimeter.

\section{$2.1 \quad$ Two-wheeled test trolley}

The primary rolling device tested, a two-wheel design, is shown in Figure 4. This design was chosen as it is an simple means of ensuring two things: that all wheels remain in contact with the floor at all times, and that the effective load on each wheel remains the same. The drawback of this design is that the trolley must be pushed by hand, which introduces a degree of variability in the trolley speed, as well as the potential for footfall noise to be registered.

The trolley consists of two wheels which area easily interchangeable, a center post where weights may be added to increase the mass of the trolley, and a push handle for maneuvering the trolley across the floor. As the trolley body consists of a hollow metal tube, it was filled with fine grain sand to eliminate ringing due to resonance while rolling. Additionally, as the wheels of the trolley turn on a rigid axle (i.e. there are no wheel bearings or suspension involved), the axle was wrapped in Teflon tape to eliminate rattling between the wheel and axle. These two modifications ensured that the only noise being generated during rolling was the rolling noise itself. The mass of the empty trolley (with no added weights) was $7 \mathrm{~kg}$.

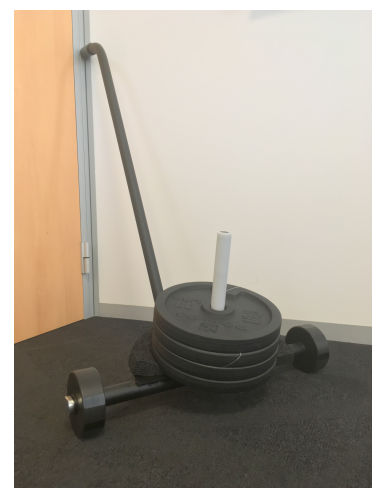

Figure 4: Two wheeled trolley used for rolling noise tests: shown here with $20 \mathrm{~kg}$ added mass.

Two types of cylindrical wheels were used on this trolley: one with a smooth profile, and one with six $0.5 \mathrm{~mm}$ flat spots positioned non-periodically around the wheel's circumference. Schematics of these are shown in Figure 5. The latter was included as a means of including the effect of wheel flats on the generated rolling noise. Both wheels had a $50 \mathrm{~mm}$ radius and $35 \mathrm{~mm}$ width.

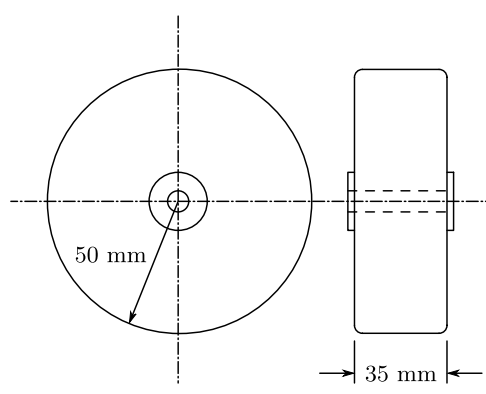

(a) Smooth wheel

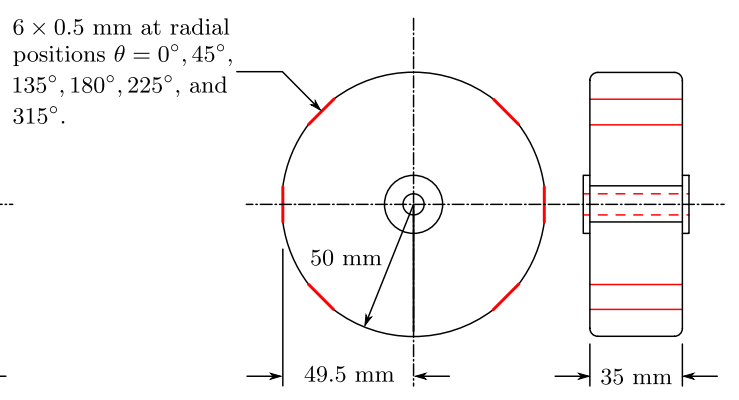

(b) Flat wheel

Figure 5: Diagrams of the wheels used on the two-wheeled test trolley. Flat spots shown in bold and in red for clarity. 
The trolley was rolled linearly in a forward and backward motion for a duration of at least 30 second per run. The rolling direction was chosen so as not to split the room symmetrically, so as to reduce the effect of room modes. The rolling distance in a single direction (before stopping and rolling in the reverse direction) was $2.5 \mathrm{~m}$. A $1.5 \mathrm{~m}$ pole was attached to the handle of the trolley, which allowed the operator to push the trolley through its entire rolling distance by only taking a single step forward and/or backward.

The varying parameters of the test were the floor type, wheel type, trolley speed, and added load on the trolley. Three different mass configurations were used: 10, 20, and $30 \mathrm{~kg}$. These added loads were all in addition to the $7 \mathrm{~kg}$ mass of the trolley itself. The trolley was rolled on the bare polished concrete floor, as well as two types of PVC floor coverings: one smooth and one rough. These two floor coverings were identical in material construction: the only difference was their surface roughness. The trolley was rolled with each of the two types of plastic cylindrical wheels installed: smooth and flat.

Three different trolley speeds were used: $0.5,0.9$, and $1.6 \mathrm{~m} / \mathrm{s}$. These were selected empirically to capture "low", "medium", and "high" speed scenarios. $0.9 \mathrm{~m} / \mathrm{s}$ was first chosen as the medium speed, as observation showed that this was a comfortable speed to push the trolley while walking normally. Originally, the hypothesis was that the average preferred walking speed of humans should be used, which is $1.4 \mathrm{~m} / \mathrm{s}$ [18]. However, in preliminary testing it was found that this was actually quite a bit higher than the speed at which an operator would naturally be inclined to push a heavy trolley. The added resistance provided by the trolley resulted in a drop in preferred walking speed. This new preferred speed was found to be around $0.9 \mathrm{~m} / \mathrm{s}$. From there, speeds roughly $50 \%$ lower and $50 \%$ higher were chosen as the low and high speeds. Similar to the medium speed, these were chosen through trial and error. It was found that any lower than $0.5 \mathrm{~m} / \mathrm{s}$, and the sound level would approach the noise floor of the room, making accurate measurements difficult. Any higher than $1.6 \mathrm{~m} / \mathrm{s}$, and the trolley became difficult to operate consistently, especially with the higher added loads. Thus, the three speeds were chosen.

All permutations of the floor type, wheel type, and added load were tested for a trolley speed of $0.9 \mathrm{~m} / \mathrm{s}$. The additional speeds of 0.5 and $1.6 \mathrm{~m} / \mathrm{s}$ were tested for all floor and wheel types with an added load of $10 \mathrm{~kg}$. This resulted in a total of 30 unique measurement configurations for the two-wheeled test trolley.

To solve the issue of variability introduced by using a human operator to push the trolley, the operator wore a wireless earpiece which played a metronome set to a tempo which matched the desired rolling speed. For a rolling distance of $2.5 \mathrm{~m}$ and chosen speeds of $0.5,0.9$, and $1.6 \mathrm{~m} / \mathrm{s}$, this corresponded to tempos of 25,43 , and 74 beats per minute (BPM) respectively. By regulating the speed such that the metronome would click as the trolley reached each end of the rolling distance, as well as at the midpoint, the average speed over the course of the entire measurement would be equal to the desired trolley speed. In addition, for each configuration a total of 5 runs were conducted and averaged together. This allowed for further reduction of variability due to small differences in trolley speed.

\section{$2.2 \quad$ Three-wheeled test trolley}

In addition to the measurements performed with the two-wheeled test trolley, a different threewheeled trolley was also built and used for a number of supplemental tests. This was done to investigate additional parameters which were not easily modifiable on the two-wheeled trolley: the wheel spacing, wheel material, and rolling trajectory. The trolley is shown in Figure 6. It consisted of a simple design: three $360^{\circ}$ swivel wheels, spaced equally apart from one another, were affixed to a solid piece of medium-density fiberbood (MDF). The distance of each of the wheels from the center of the board (and the wheels themselves) could easily be changed for measuring the effect of wheel spacing and wheel material on the radiated sound level. An additional $360^{\circ}$ swivel joint was used to attach a push arm to the top side of the trolley. This, combined with the wheels, permitted the trolley to be pushed along any trajectory without the 
need for the operator to move position: thus allowing for the effect of rolling trajectory to be more easily measured.

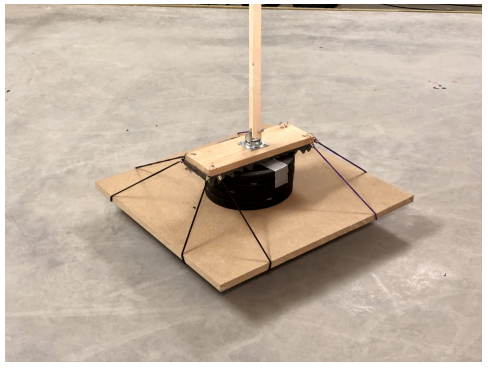

(a) Front view

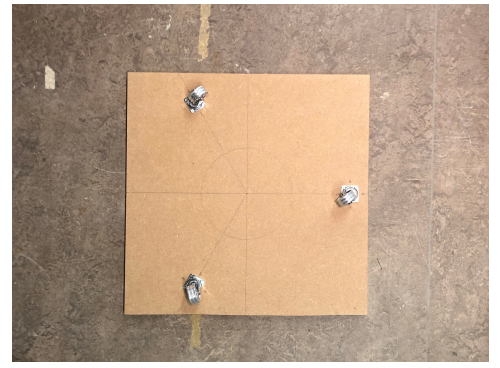

(b) Bottom view

Figure 6: Three-wheeled test trolley used for supplemental testing. The wheel type, wheel spacing, and added load were all easily interchangeable. The $360^{\circ}$ swivel wheels allowed to smoothly change the rolling trajectory without sliding between the wheels and the floor.

The varying parameters of the three-wheeled trolley tests were the wheel material, wheel spacing, and rolling trajectory. All tests were done with a $10 \mathrm{~kg}$ added load on bare concrete. Three different types of wheels were used, all of which were the same width (20 $\mathrm{mm}$ ) and radius $(25 \mathrm{~mm})$ : wood, nylon, and aluminum. Three different wheel spacings were used: placing the wheels at 120,210, and $270 \mathrm{~mm}$ from the center of the MDF (the angular spacing stayed constant at $120^{\circ}$ ). The trolley was rolled in two trajectories: linear and circular.

For the circular trajectory, the operator stood in the center of the floor and rotated the trolley around him in a constant circular fashion at a radius of $1 \mathrm{~m}$. The trolley was rolled in this trajectory for a duration of at least 30 second per run. For both linear and circular trajectories, the same metronome technique was used as before to ensure the operator was pushing the trolley at a constant speed of $0.9 \mathrm{~m} / \mathrm{s}$. This corresponded to $43 \mathrm{BPM}$ for the linear trajectory (with four clicks per period) and $72 \mathrm{BPM}$ for the circular trajectory (with eight clicks per period).

All three wheel spacings were measured for the nylon wheel on concrete in a circular trajectory. All three wheel materials were measured for the $210 \mathrm{~mm}$ wheel spacing in a circular trajectory. The nylon wheel with a $210 \mathrm{~mm}$ wheel spacing was measured for both linear and circular trajectories. Finally, all three wheel spacings were measured with the nylon wheel in a circular trajectory. This resulted in a total of 6 unique measurement configurations for the three-wheeled test trolley.

\section{$2.3 \quad$ Rolling household items}

As a final supplemental test, a number of common rolling household items were measured. This was done to observe the range of sound levels and spectral content exhibited by different indoor rolling devices. The items measured, shown in Figure 7, were as follows: an office chair, a delivery cart, a push dolly, a suitcase, a toy truck, and a vacuum cleaner. All items were rolled on concrete in a linear trajectory at a speed of $0.9 \mathrm{~m} / \mathrm{s}$. Similar to the test trolleys, measurements were conducted over a period of at least 30 seconds.

\section{Surface roughness}

Table 1 shows a number of calculated statistical roughness parameters for the two-wheeled test trolley wheel, as well as the three floors used in this study. The wheels from the three-wheeled test trolley were unfortunately not able to be measured. These profiles were measured using a Nikon LC15DX 3D scanner with an average spatial resolution of $22 \mu \mathrm{m}$. In the table, $S a$ 

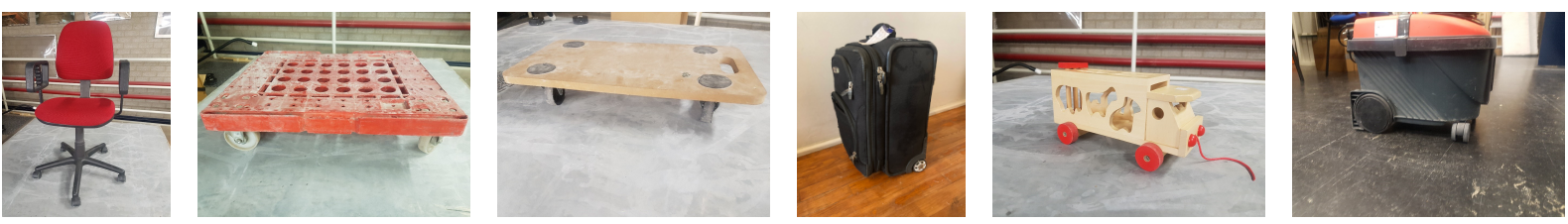

Figure 7: Household objects measured in the preliminary test. From left to right: office chair, delivery cart, push dolly, suitcase, toy truck, vacuum cleaner.

is the arithmetical mean deviation from the center-line of the roughness profile. $S q$ is the root mean squared (RMS) deviation from the center-line of the roughness profile. $S v$ is the arithmetical minimum value of the profile, or maximum valley depth. $S p$ is the arithmetical maximum value of the profile, or maximum peak height. $S z$ is the arithmetical sum of $S v$ and $S p$, or maximum height. $S s k$ is the skewness: a measure of the asymmetry of the probability distribution of the profile about its mean. In general, a negative skewness indicates that the probability distribution function has a tail which skews left of the mean, and a positive skewness indicates that the probability distribution function has a tail which skews right of the mean. $S k u$ is the kurtosis: a measure of the tailedness of the probability distribution of the profile about its mean. In effect, it measures the influence of the outliers of the data-set. All of these parameters are defined in ISO 4287 [19]. They are based on the mean-line system. That is, they depend on the deviations of the peaks and valleys from the mean.

Finally, $H$ is the Hurst exponent. It is defined in terms the asymptotic behavior of the rescaled range of the span of a series [20]. It may be thought of as a measure of the randomness of the profile. It describes the likelihood of a series to either regress back towards the mean or to move in a certain direction. $0.5<H<1$ denotes a profile with positive autocorrelation, or in other words, that a large value at point $i$ is likely to be followed by another large value at point $i+1$. Conversely, $0<H<0.5$ denotes the opposite: a profile with negative autocorrelation, which is constantly switching back and forth between large and small values, one after the other. $H=0.5$ denotes an uncorrelated profile (i.e. one with no autocorrelation): the magnitude of point $i$ provides no information about the magnitude of point $i+1$ [21]. In practice, the Hurst exponent for the measured roughness profiles was estimated here in MATLAB using [22], which was developed from $[23,25,26]$.

Table 1: Statistical roughness parameters

\begin{tabular}{lrrrrrrrr}
\hline & $\begin{array}{c}S a \\
{[\mu \mathrm{m}]}\end{array}$ & $\begin{array}{c}S q \\
{[\mu \mathrm{m}]}\end{array}$ & $\begin{array}{c}S v \\
{[\mu \mathrm{m}]}\end{array}$ & $\begin{array}{c}S p \\
{[\mu \mathrm{m}]}\end{array}$ & $\begin{array}{c}S z \\
{[\mu \mathrm{m}]}\end{array}$ & $\begin{array}{c}\text { Ssk } \\
{[-]}\end{array}$ & $\begin{array}{c}S k u \\
{[-]}\end{array}$ & $\begin{array}{c}H \\
{[-]}\end{array}$ \\
\hline Rough PVC & 42.1 & 51.1 & 247.1 & 237.0 & 484.2 & 0.3 & 2.6 & 0.7 \\
Smooth PVC & 9.2 & 12.3 & 301.1 & 183.4 & 484.5 & -0.4 & 8.5 & 0.5 \\
Plastic wheel: & 6.6 & 10.5 & 332.2 & 351.6 & 683.8 & -0.8 & 28.1 & 0.4 \\
two-wheel test trolley & & & & & & & & \\
Polished concrete & 2.0 & 3.0 & 303.9 & 123.9 & 427.8 & -8.3 & 668.4 & 0.3 \\
\hline
\end{tabular}

These values are used in the field of surface metrology to varying degrees to describe a given profiles surface roughness. All except the Hurst exponent exhibit the drawback that they will be skewed by a single large asperity, giving the impression that the entire profile is rougher than it actually is in reality.

The order of profiles from least to most rough are: polished concrete, plastic wheel, smooth PVC, and rough PVC. Comparing $S a$ and $S q$ with $S v, S p$, and $S z$ for the polished concrete reveals that the statistical values are being dominated by a single large asperity. The mean and RMS values are very low, while the maximum and kurtosis values are quite high. A similar phenomenon exists (though to a lesser degree) for the plastic wheel as well.

The plastic wheel has little autocorrelation, as evidenced by a Hurst exponent close to 0.5. A 
given roughness asperity provides little information about what an adjacent roughness asperity will look like. The same can be said of the smooth PVC. The polished concrete is moderately negatively autocorrelated, lending to its generally smooth nature. The rough PVC, by contrast, is moderately positively correlated.

\section{Test results}

The primary quantity of interest is the normalized sound pressure level $L_{n}$ [4], provided by Equation (1). This takes into account the absorption of the reception room. Additionally, results for the relative normalized sound pressure level $\Delta L$ in the reception room [14], provided by Equation (2), are given for a select number of configurations. This yields the relative benefit of applying a floor covering by subtracting the measured $L_{n}$ of the trolley rolling with the floor covering in place from the measured $L_{n, 0}$ of the trolley rolling on bare concrete.

\subsection{Two-wheeled test trolley}

Figure 8 shows the normalized sound pressure level in the reception room from the two-wheeled trolley for all floor and wheel types. For all of these runs, the trolley speed was $0.9 \mathrm{~m} / \mathrm{s}$ and the added load was $10 \mathrm{~kg}$. The spectra of the background noise and noise generated due to the stepping of the operator alone (called "walking" here) are also shown.

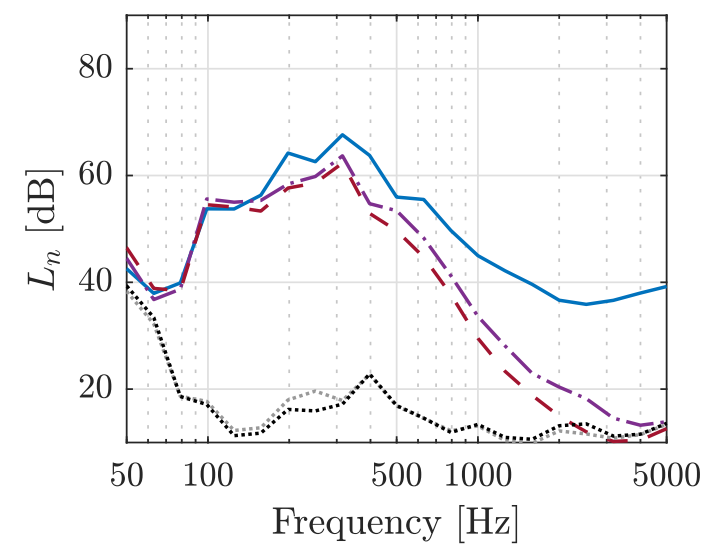

(a) Smooth wheel

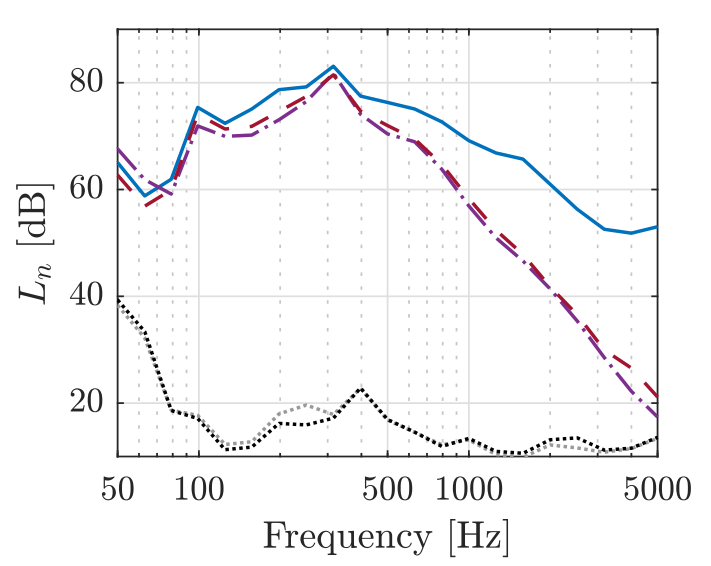

(b) Flat wheel

Figure 8: Normalized sound pressure level of the two-wheeled trolley for varying floor and wheel type. All runs were done with a trolley speed of $0.9 \mathrm{~m} / \mathrm{s}$ and an added load of $10 \mathrm{~kg}$. - Concrete, ---- Concrete + rough PVC, - - - Concrete + smooth PVC, ............ walking, ……... background.

Several observations may be made from these graphs. The noise generated due to the walking of the operator is negligible. Both PVC floor coverings provided a reasonable benefit over the bare concrete alone above $200 \mathrm{~Hz}$ due to their lower elasticities: the two PVC curves in the $L_{n}$ plot begin to trend downward relative to the concrete curve above this frequency. It is worth noting here that the elasticity of concern is primarily that of the top layer. A similar overall elasticity could theoretically be achieved for the whole floor system by adding a soft decoupling layer between two hard outer layers (e.g. a concrete base layer, a fiberwood intermediate layer, and a tile top layer). However, this would generate a different effect due to wheel rolling contact with the hard top layer.

In the case of the smooth wheel the rough PVC was an average of $2.3 \mathrm{~dB}$ louder than the smooth PVC. However, this difference was negligible for the flat wheel. The smooth and rough PVC, however, were an average of 11.2 and $8.9 \mathrm{~dB}$ quieter than the bare concrete for the case 
of the smooth wheel. For the flat wheel they where an average of 10.4 and $9.6 \mathrm{~dB}$ quieter, respectively. Considering the only difference between these two floor coverings is their surface roughness, it may be concluded that the elasticity of a given floor layer (or of the wheel) has a greater influence on the radiated sound than its surface roughness. That is to say, the surface roughness has a low influence on the generated sound level when the floor and/or wheel is soft.

The presence of wheel flats had a far greater effect on the radiated sound than the type of floor used. The flat wheel rolling on the soft PVC was on average $10 \mathrm{~dB}$ louder than the smooth wheel rolling on the bare concrete. For this test, the PVC provided a similar benefit over the bare concrete in the case of both smooth and flat wheels. This suggests that the effect of adding a floor covering may be more or less independent of the wheel type. In some cases (e.g. with the PVC floor coverings in place) the smooth wheel was not able to generate a sufficiently high sound level at high frequencies to emerge from the background noise level. In such a scenario, using a rolling source with flat spots on the wheels yields a more elevated sound level; providing a sufficient signal-to-noise ratio (SNR) for reliable measurement data on resilient floor systems.

The experimental tests showed very low variation between of the five repeated runs for a given configuration. Average standard deviations of the normalized sound pressure level $L_{n}$ were generally less than or equal to $1 \mathrm{~dB}$, with only one configuration (rough PVC floor, smooth wheel, $0.9 \mathrm{~m} / \mathrm{s}$ trolley speed, and $10 \mathrm{~kg}$ added load) having a slightly higher standard deviation of $1.3 \mathrm{~dB}$. This validated the method of using a metronome as an effective means of controlling the trolley speed.

Figure 9 shows the relative benefit of adding the two PVC floor coverings when compared to concrete for the two-wheeled trolley. Calculating $\Delta L$ is important because it demonstrates that a tapping machine is not sufficient for characterizing a given floor's response to rolling noise. Here the smooth and rough PVC floors provide different attenuations for the smooth wheel: the smooth PVC provides a benefit over the concrete in this situation which is $3.8 \mathrm{~dB}$ greater on average in the range of $400-5000 \mathrm{~Hz}$ than the rough PVC. The results for the flat wheel, however, do not exhibit this difference. The profile of the wheel flat spot dominates in this situation, overriding any difference the surface roughness may cause. A tapping machine test would yield similar results, and would falsely conclude that the two PVC floor coverings would perform equally well against rolling noise. With respect to rolling noise, $\Delta L$ is not an intrinsic property of the floor (as is the case with impact noise): the excitation is strongly coupled to the floor. The trolley cannot be considered to be an independent source due to the influence of the surface roughness of both the wheel and the floor. The goal of this paper is not to characterize floors per se. However, as floor characterization is the ultimate goal of a standard rolling device, the $\Delta L$ plot has been included here to demonstrate the test trolley's usefulness in measuring such a parameter.

Figure 10 shows the normalized sound pressure level in the reception room for varying added loads with both smooth and flat wheels. The trolley speed was $0.9 \mathrm{~m} / \mathrm{s}$. The large difference between smooth and flat wheels for all loads can once again be seen. Perhaps counter-intuitively, varying the load does not greatly change the radiated sound level. For the case of the smooth wheel, increasing the load by $10 \mathrm{~kg}$ causes a $2-3 \mathrm{~dB}$ reduction in sound level in the range of $100-$ $500 \mathrm{~Hz}$. The flat wheel exhibited essentially no noticeable change in sound level with changing load. As the load increases, new roughness asperities come into contact with one another which were out of contact at lower loads, resulting in a small reduction in sound level at mid-to-low frequencies.

Figure 11 shows the normalized sound pressure level in the reception room due to rolling noise for varying trolley speed in the case of both a smooth and flat wheel. For all of these runs, the added load was $10 \mathrm{~kg}$. The high influence that the trolley speed has on the radiated sound level becomes apparent here. The effect of the speed may even eclipse the effect of the wheel type for mid to high frequencies if the speed difference is sufficiently large: for example, when comparing the smooth wheel at $1.6 \mathrm{~m} / \mathrm{s}$ to the flat wheel at $0.5 \mathrm{~m} / \mathrm{s}$. Raising the speed results in 


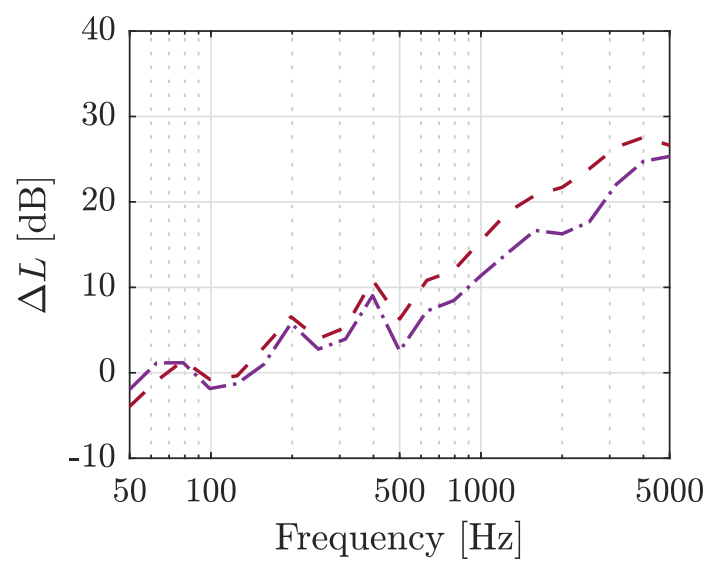

(a) Smooth wheel

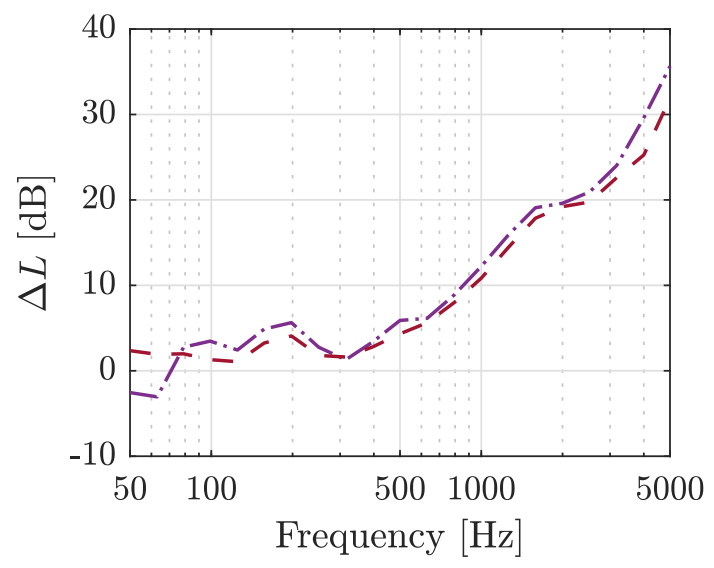

(b) Flat wheel

Figure 9: Relative benefit of adding rough and smooth PVC floor coverings vs the concrete floor for the two-wheeled trolley. All runs were done with a trolley speed of $0.9 \mathrm{~m} / \mathrm{s}$ and an added load of $10 \mathrm{~kg} .{ }^{-\cdot-\cdot-}$ Rough PVC, - - - smooth PVC.

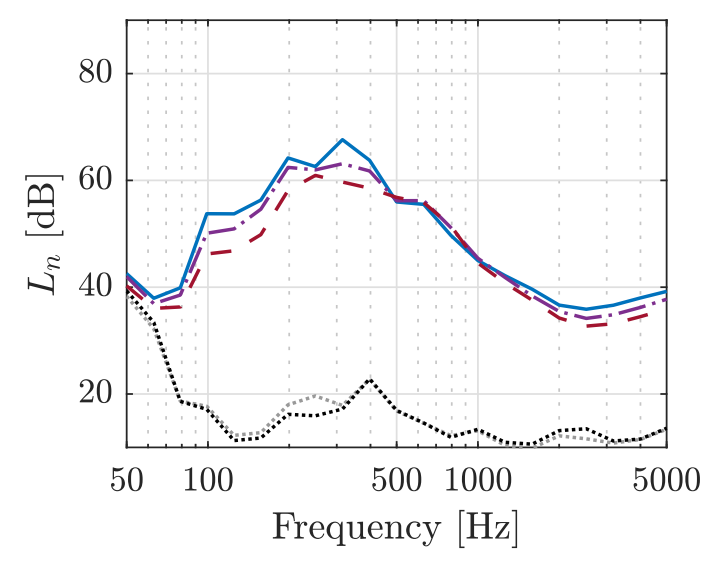

(a) Smooth wheel

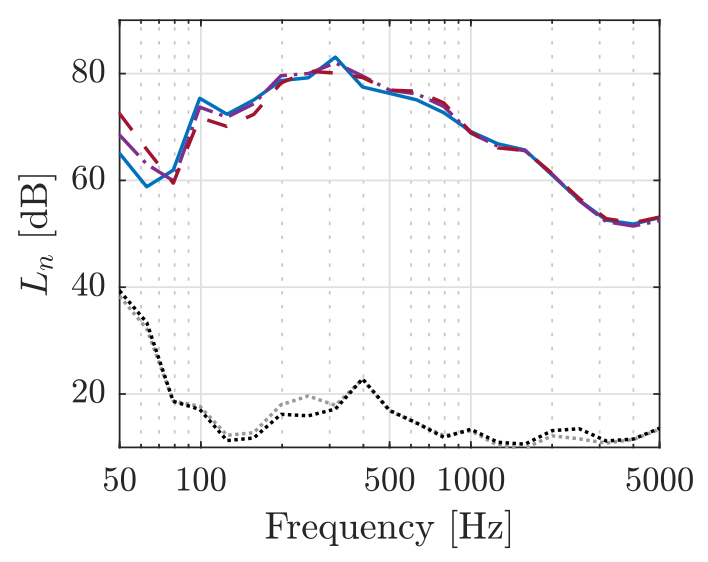

(b) Flat wheel

Figure 10: Normalized sound pressure level of the two-wheeled trolley for varying added mass. All runs were done on bare concrete with a trolley speed of $0.9 \mathrm{~m} / \mathrm{s}$. $-10 \mathrm{~kg},-\cdot-\cdot 20 \mathrm{~kg}$, - - - $30 \mathrm{~kg}$, ……... walking, ……... background.

a broadband increase in sound level for a given wheel type. Interestingly, there is no measurable frequency shift with changing trolley speed. In theory the frequency should increase with speed, as the excitation is directly related to the roughness wavelengths excited in the contact area (being a function of the trolley speed). However, this effect is either not present here, or so small that it cannot be observed at the measured speeds.

\subsection{Three-wheeled test trolley}

Figure 12 shows the normalized sound pressure level in the reception room due to rolling noise of the three-wheeled trolley for linear and circular trajectory. For all of these runs the floor was concrete, the trolley speed was $0.9 \mathrm{~m} / \mathrm{s}$, the added load was $10 \mathrm{~kg}$, the wheel spacing was $210 \mathrm{~mm}$, and the wheel material was nylon. The spectra of the background noise and operator noise are also shown. As it was already determined that stepping in the linear trajectory had no noticeable effect, here the spectrum from stepping in the circular trajectory is shown. The operator needed to continuously rotate his body in place to keep facing the trolley as it traversed the circular 


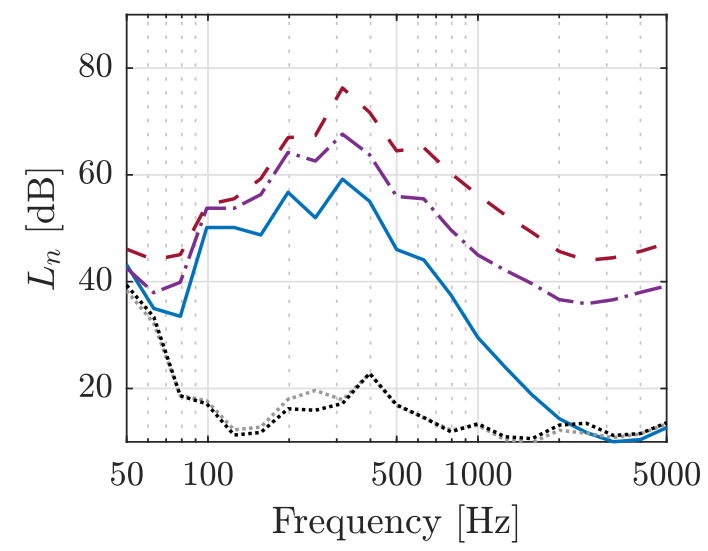

(a) Smooth wheel

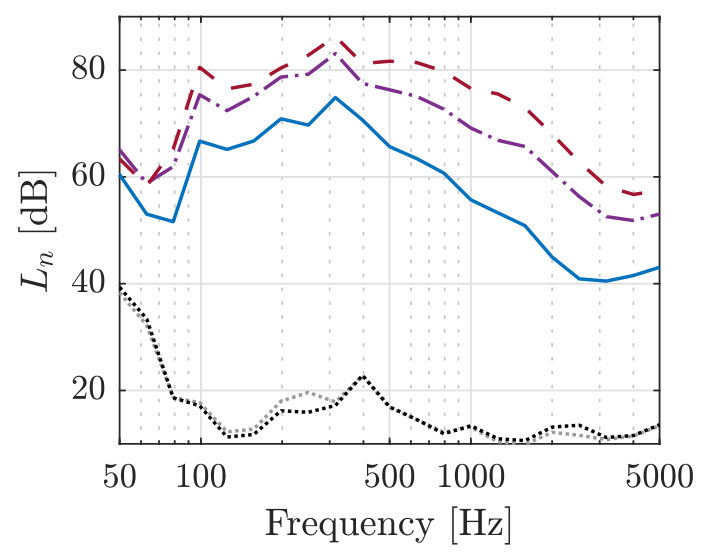

(b) Flat wheel

Figure 11: Normalized sound pressure level of the two-wheeled trolley for varying trolley speed. All runs were done on bare concrete with an added load of $10 \mathrm{~kg}$. - $0.5 \mathrm{~m} / \mathrm{s},---\cdot 0.9 \mathrm{~m} / \mathrm{s}$,

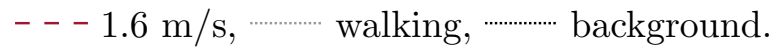

path. Finally, the two-wheeled trolley is also shown (linear trajectory) for comparison.

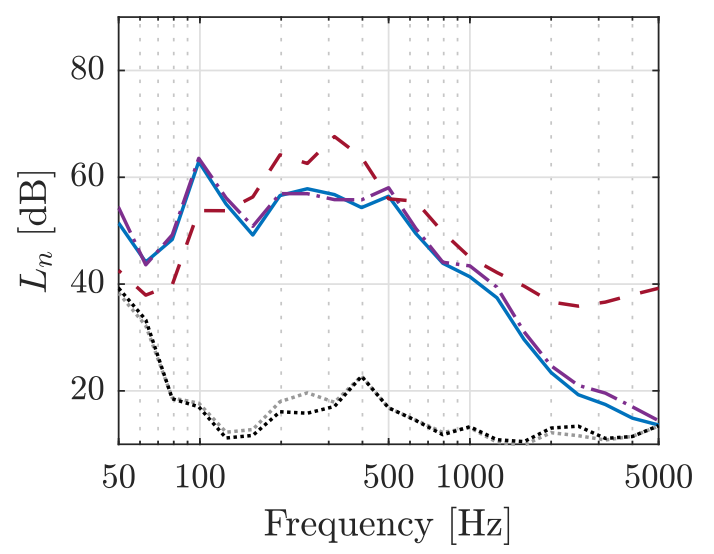

Figure 12: Normalized sound pressure level of the three-wheeled test trolley for varying rolling trajectory. All runs were done on the concrete floor with a $10 \mathrm{~kg}$ added load, $0.9 \mathrm{~m} / \mathrm{s}$ trolley speed, $210 \mathrm{~mm}$ wheel spacing, and nylon wheel material. The two-wheeled trolley (linear trajectory) is also shown for comparison. - three-wheeled linear, ----- three-wheeled circular, - - - two-wheeled linear, ……”. walking, ……… background.

There is very little difference between the sound spectra for the three-wheeled trolley linear and circular trajectories: they are nearly identical. In the velocity range at play here, there is a direct relationship between the speed of the trolley and its radiated sound level. Thus, as long as the average speed over a set measurement duration is the same, it may be assumed that the amount of acoustic energy will be the same as well. The comparison with the two-wheeled trolley shows that even with different trolley designs, a similar bell shaped curve is still achieved.

The hypothesis here was that a circular trajectory would be more representative of a trolley rolling in a straight line of infinite length than a back-and-forth linear trajectory of finite length. The results of these tests reject this hypothesis: both a back-and-forth linear trajectory and a circular trajectory are equally representative of an infinitely long linear trajectory. At this stage the decision of which trajectory to use in a standard is still open. These results show that this decision can instead be made by other engineering considerations (e.g. ease of automation) without changing the device's sound signature. 
Figure 13 shows the normalized sound pressure level in the reception room due to rolling noise from the three-wheeled trolley for the nylon, wood, and aluminum wheels. For all of these runs the trolley speed was $0.9 \mathrm{~m} / \mathrm{s}$, the added load was $10 \mathrm{~kg}$, the wheel spacing was $210 \mathrm{~mm}$, and the rolling trajectory was circular.

The relationship between wheel material and radiated sound level is well established [24]. More specifically, what matters is the apparent Young's modulus $E^{\prime}=\left(\frac{1-\nu_{\text {wheel }}^{2}}{E_{\text {wheel }}}+\frac{1-\nu_{\text {floor }}^{2}}{E_{\text {floor }}}\right)^{-1}$, being a function of the Young's moduli and Poisson's ratio of both the wheel and floor. A higher $E^{\prime}$ causes a greater injected force into the floor, leading to a higher excitation. As the elasticity of the wheel increases, the radiated sound level should increase as well at higher frequencies. This is exactly what is demonstrated here $\left(E_{\text {aluminum }} \approx 70 \mathrm{GPa}, E_{\text {wood }} \approx 10 \mathrm{GPa}\right.$, and $\left.E_{\text {nylon }} \approx 2 \mathrm{GPa}\right)$. The effect of Young's modulus may be thought of here as analogous to a soft impact for a low $E^{\prime}$ (with low energy at high frequencies) and a hard impact for a high $E^{\prime}$ (which increases the energy at high frequencies).

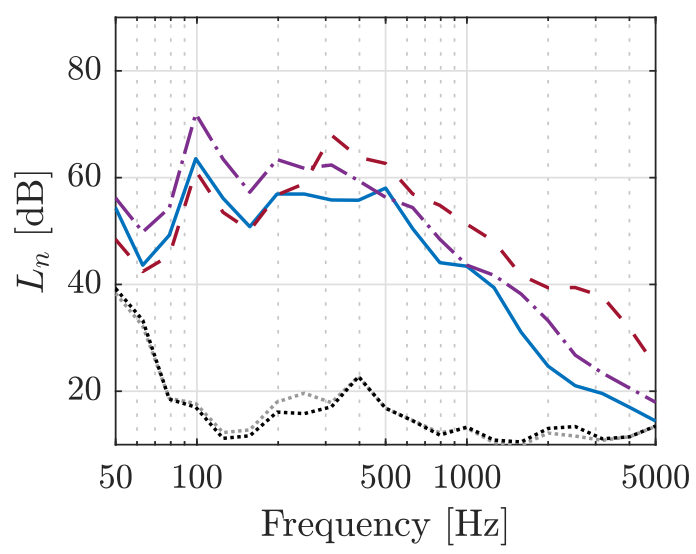

Figure 13: Normalized sound pressure level of the three-wheeled test trolley for varying wheel material. All runs were done with a $10 \mathrm{~kg}$ added load, $0.9 \mathrm{~m} / \mathrm{s}$ trolley speed, $210 \mathrm{~mm}$ wheel

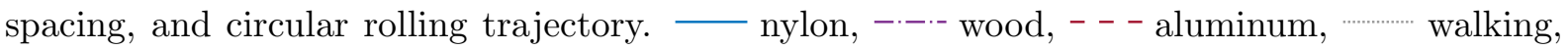
............ background.

While the effect of a changing Young's modulus is realized across the entire frequency spectrum for the wood and nylon wheels, the same cannot be said for the aluminum wheel. The aluminum wheel has a greater amount of acoustic energy above $250 \mathrm{~Hz}$, but is equivalent to the nylon wheel at lower frequencies. It is possible that this discrepancy may be explained by the differences in roughness profiles, which unfortunately were not measured for these wheels. If the long wavelength asperities of the aluminum wheel's roughness profile are less significant than those of the wood and nylon wheel, less acoustic energy would be radiated in the low frequency range.

Figure 14 shows the normalized sound pressure level in the reception room due to rolling noise from the three-wheeled trolley for the 120, 210, and $270 \mathrm{~mm}$ wheel spacings. For all of these runs the floor was concrete, the trolley speed was $0.9 \mathrm{~m} / \mathrm{s}$, the added load was $10 \mathrm{~kg}$, the wheel material was nylon, and the rolling trajectory was circular. The null hypothesis was that wheel spacing would not play a significant role in the radiated sound level. This turned out to not entirely be the case: enlarging the wheel spacing did mildly increase the radiated sound level in the range of 100-300 $\mathrm{Hz}$ : an average of $3.7 \mathrm{~dB}$ from 120 to $210 \mathrm{~mm}$, and $1.7 \mathrm{~dB}$ from 210 to $270 \mathrm{~mm}$ in this frequency range. The opposite effect occurred below $100 \mathrm{~Hz}$, though this result is less reliable considering the high modal behavior of the room volume in this frequency range.

Changing the wheel spacing changes the structural modes being excited on the floor. The wheel spacings only differ by $60-150 \mathrm{~mm}$; however in some cases, such as this one, it is enough 


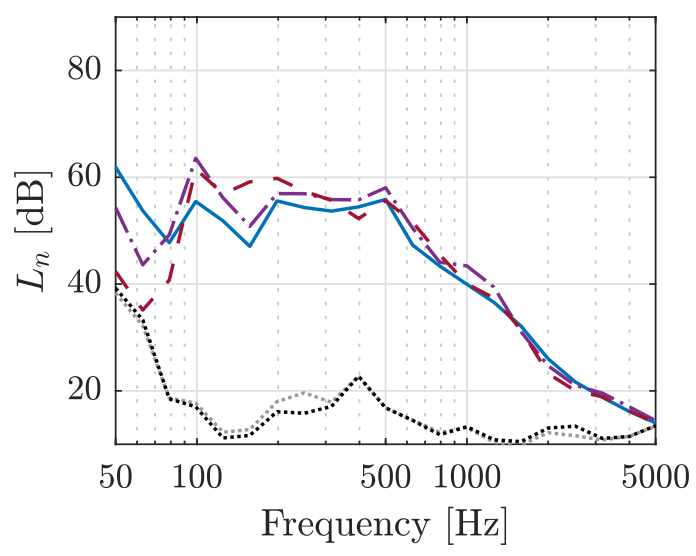

Figure 14: Normalized sound pressure level of the three-wheeled test trolley for varying wheel spacing. All runs were done on the concrete floor with a $10 \mathrm{~kg}$ added load, $0.9 \mathrm{~m} / \mathrm{s}$ trolley speed, nylon wheel material, and circular rolling trajectory. —- $120 \mathrm{~mm},-\cdot-\cdot 210 \mathrm{~mm},-$ - $^{-} 270 \mathrm{~mm}$, .......... walking, ........... background.

to cause a difference in radiated sound level. These results show that floor mobility becomes increasingly influential as frequency decreases. This effect will be even greater on light-weight timber floors. Increasing the rigidity of the trolley would help to minimize this effect, though it cannot be fully eliminated. The floor will always exhibit some vibration under structural excitation.

\subsection{Modal analysis}

A modal analysis of the floor was conducted via ISO 7626-2[27] in order to identify the degree to which its vibration contributes to the shapes of the $L_{n}$ curves seen in the rolling test results. Figure 15 shows the exciter and receiver positions used. Drive-point measurements were conducted at each position and the results averaged to obtain the total floor mobility.

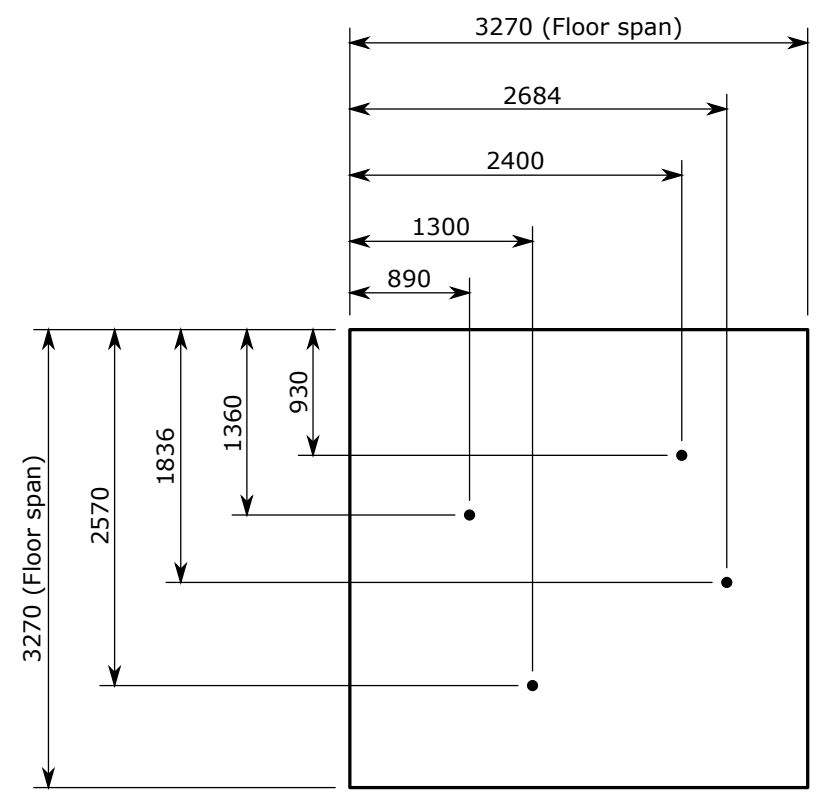

Figure 15: Exciter and receiver positions on the concrete floor used for the impact hammer test via ISO 7626-2[27]. Drive-point measurements were conducted at each position and the results averaged to obtain the total floor mobility. All dimensions are in millimeters. 
Figure 16 shows the mobility of the $100 \mathrm{~mm}$ concrete slab used in the study. The floor mobility exhibits large peaks in the $50-500 \mathrm{~Hz}$ frequency range where much of the acoustic energy is located from the two and three wheeled trolley results; the largest of these being at $100 \mathrm{~Hz}$.

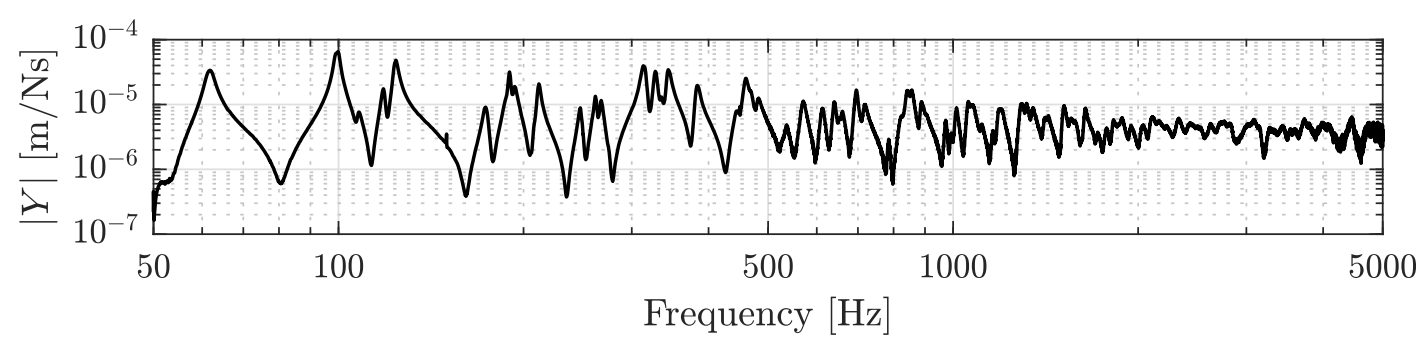

Figure 16: Mobility of the $100 \mathrm{~mm}$ concrete slab, measured with an impact hammer test via ISO 7626-2[27].

Figure 17 shows a comparison of the narrow band sound pressure level of the two and three wheeled test trolleys with the floor vibrational modes. The modal frequencies of the floor from Figure 16 are indicated here (up to $500 \mathrm{~Hz}$ ) with vertical dot-dash lines. There is a strong congruency between the $L_{P}$ curves and the floor mobility. The primary outlier is the $63 \mathrm{~Hz}$ floor mode, which is not present in any of the $L_{P}$ curves. In particular, Figure 16 helps explain the peaks at the $100 \mathrm{~Hz}$ 1/3 octave band in Figures 8 and 10 to 14 .

Considering the high congruency among peaks between Figures 16 and 17, it is assumed that the vibration of the floor dominates over the vibration of the trolley frame with respect to the influence on radiated sound level. Care should indeed be taken to ensure a trolley frame design which minimizes the magnitude of vibrational modes in the main frequency range of interest for rolling noise. However, their effect will nevertheless remain minimal compared to those of the floor.

\subsection{Rolling household items}

Figure 18 shows the normalized sound pressure level in the reception room from each of the rolling household items on concrete. The spectrum of the background noise is also shown. Finally, the two-wheel and three-wheel test trolleys are shown for comparison. All items were rolled in a linear trajectory. There is a large degree of variation between the sound levels of the various household items: there is an average difference of $27 \mathrm{~dB}$ between the loudest and smallest curves across the entire frequency range. There is no one single sound signature for indoor rolling noise. The curves do all carry the same general shape: with most of the acoustic energy in the range of 100-400 Hz, then sloping off thereafter in the higher frequencies. However, indoor rolling noise can still come in many shapes and sizes depending on the exact characteristics of the excitation source.

The household items measured here all had different masses, wheel sizes, wheel materials, numbers of wheels, and wheel surface roughness profiles. All of these factors contribute to the variations seen in Figure 18. These variations show the necessity of performing more regulated testing with the two and three wheeled trolleys. Having a device which can control for these variables allows the effect of each one to be observed individually.

This means that the goal of developing a standard rolling device is not to capture the entire spectrum of possible rolling profiles. Such a device would need to be extremely modular and thus would no longer fulfill the requirements of simplicity and regularity. Rather, the goal is to reproduce a "worst case scenario" by generating as loud a rolling noise as possible while distinguishing between floors. This allows the device to produce usable results on both heavy and light-weight construction floors. 


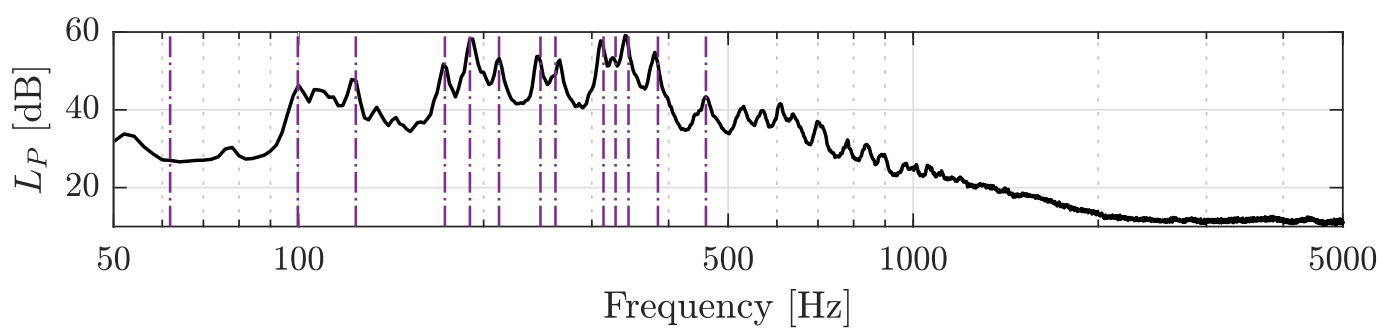

(a) Two-wheeled test trolley: $10 \mathrm{~kg}$ added load, $0.9 \mathrm{~m} / \mathrm{s}$ trolley speed.

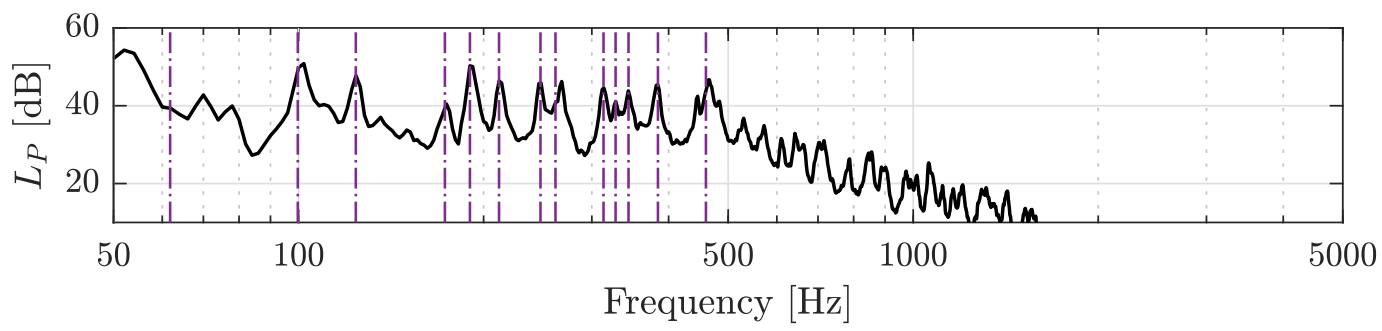

(b) Three-wheeled test trolley: $10 \mathrm{~kg}$ added load, plastic wheel, circular trajectory, $120 \mathrm{~mm}$ wheel spacing.

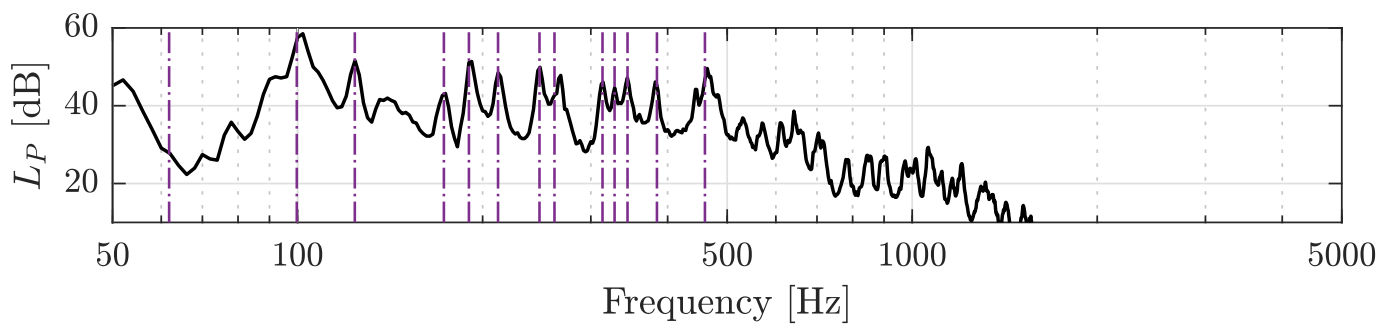

(c) Three-wheeled test trolley: $10 \mathrm{~kg}$ added load, plastic wheel, circular trajectory, $210 \mathrm{~mm}$ wheel spacing.

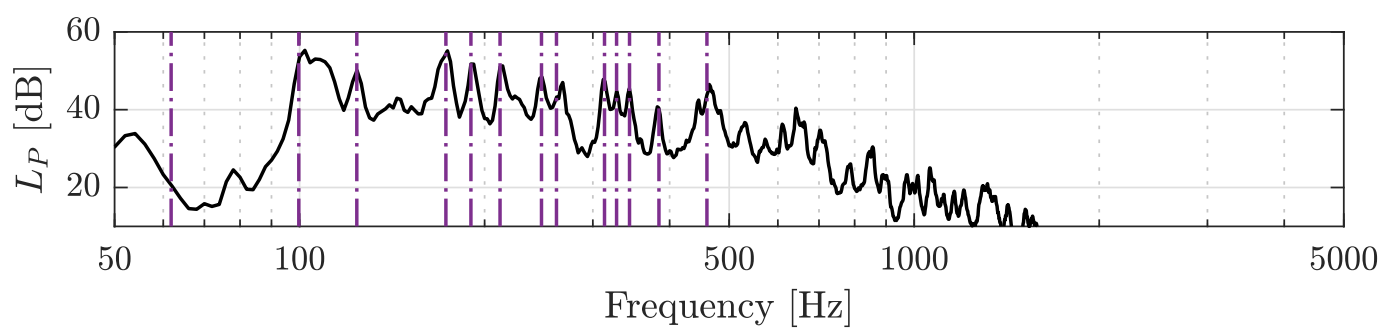

(d) Three-wheeled test trolley: $10 \mathrm{~kg}$ added load, plastic wheel, circular trajectory, $270 \mathrm{~mm}$ wheel spacing.

Figure 17: Comparison of the narrow band sound pressure level of the two and three wheeled test trolleys $(-)$ with floor vibrational modes (-----).

\section{Discussion}

At its most basic level, a standard rolling noise device should perform a simple function: it should roll across the floor of the emission room while generating a sound that can be measured in the reception room below. There are countless ways which this can be achieved. The goal here is not to come up with the design for the prototype itself, but rather to propose a methodology for creating one, and present a discussion of what the priorities should be in the engineering process in order to ensure that, when the times comes, the device that ends up being developed is worthwhile. 


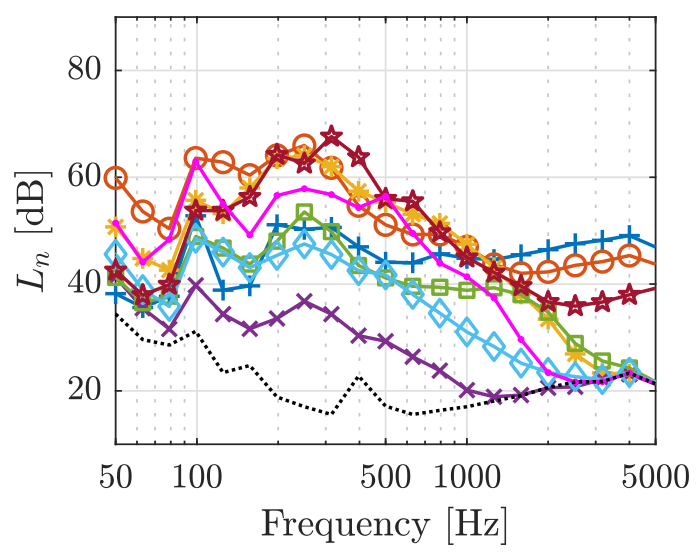

Figure 18: Normalized sound pressure level of the household items measured in the preliminary rolling noise test. Two-wheel and three-wheel trolleys shown for comparison. chair, $-\odot$ delivery cart, $\rightarrow$ push dolly, $\rightarrow$ - suitcase, $\square$ - toy truck, $-\bullet$ vacuum cleaner,

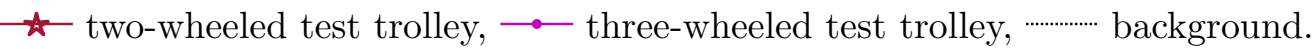

\subsection{Lessons learned from the tapping machine}

An extensive history of the development of the tapping machine was published by Theodore J. Schultz in his report "Impact Noise Testing and Rating - 1980" [28]. This report presents a detailed discussion on some of the most important considerations identified throughout the development of the tapping machine. A comparison between the tapping machine and a proposed rolling machine in regards to these considerations is summarized in Table 2.

Table 2: Lessons learned from the tapping machine

\begin{tabular}{|c|c|c|}
\hline & Tapping machine & Rolling machine \\
\hline $\begin{array}{l}\text { Influencing } \\
\text { parameters }\end{array}$ & $\begin{array}{l}\text { Hammer mass } \\
\text { Hammer material } \\
\text { Hammer drop height } \\
\text { Frequency of impacts } \\
\text { Floor construction }\end{array}$ & $\begin{array}{l}\text { Wheel/floor material properties } \\
\text { Wheel/floor surface roughness } \\
\text { Wheel/floor geometry } \\
\text { Trolley speed } \\
\text { Trolley mass }\end{array}$ \\
\hline Source & Tapping machine & $\begin{array}{l}\text { Rolling machine } \\
\text { Floor (via surface roughness) }\end{array}$ \\
\hline Transfer path & Floor & Floor \\
\hline $\begin{array}{l}\text { Poor accuracy } \\
\text { occurs when } \\
\text { device... }\end{array}$ & $\begin{array}{l}\text { Does not truly replicate footfall } \\
\text { noise (fall energy too great) }\end{array}$ & $\begin{array}{l}\text { Does not truly replicate rolling } \\
\text { noise (effect of wheel flat spots } \\
\text { too dominant) }\end{array}$ \\
\hline $\begin{array}{l}\text { Poor repeatability } \\
\text { occurs if device... }\end{array}$ & $\begin{array}{l}\text { Yields different results between } \\
\text { labs (under-controlled floor } \\
\text { construction) }\end{array}$ & $\begin{array}{l}\text { Yields different results between } \\
\text { labs (under-controlled floor } \\
\text { surface roughness) } \\
\text { Yields different results between } \\
\text { runs (under-controlled speed) }\end{array}$ \\
\hline
\end{tabular}

Identification of the primary influencing parameters of a given type of excitation is the first step in developing a device which can reproduce such excitation in a standardized way. Some characteristics are similar between tapping and rolling excitation (e.g. mass and material properties), but others differ (e.g. surface roughness). The two share the same transfer path (through the floor), but differ with regards to the source. With rolling noise, a change in floor results in a change in transfer path and a change in source, due to the fact that the floor's 
surface roughness plays a role in the rolling excitation.

Throughout the development of the tapping machine, a pattern emerged for a consistent preference of repeatability over accuracy. It is better that the device generate a consistent, but unrealistically high excitation (providing a sufficient SNR in all situations), rather than generate a realistic excitation which cannot be easily controlled or measured on certain floors. For rolling excitation, this requires that the device have a tightly controlled surface roughness, rolling speed, and the option to use wheels with flat spots on heavy-weight floors. For additional discussion on the development of the tapping machine as an influence for developing a standard rolling device, see [29]. The most relevant considerations from this report have been addressed in the discussion here.

\subsection{Specific considerations for a standard rolling noise device}

The overall goal in developing a standard rolling device is to replicate a "worst case scenario". That is, the device should generate as loud a rolling noise signature as possible. This allows the device to still yield meaningful results for both light-weight and heavy-weight floors. Figure 19 summarizes the specific considerations for a standard rolling device identified in this paper. The primary characteristics of rolling noise examined in the measurements provide design guidelines regarding the construction of the device: the number of wheels, wheel material \& profile, mass, trajectory, and speed.

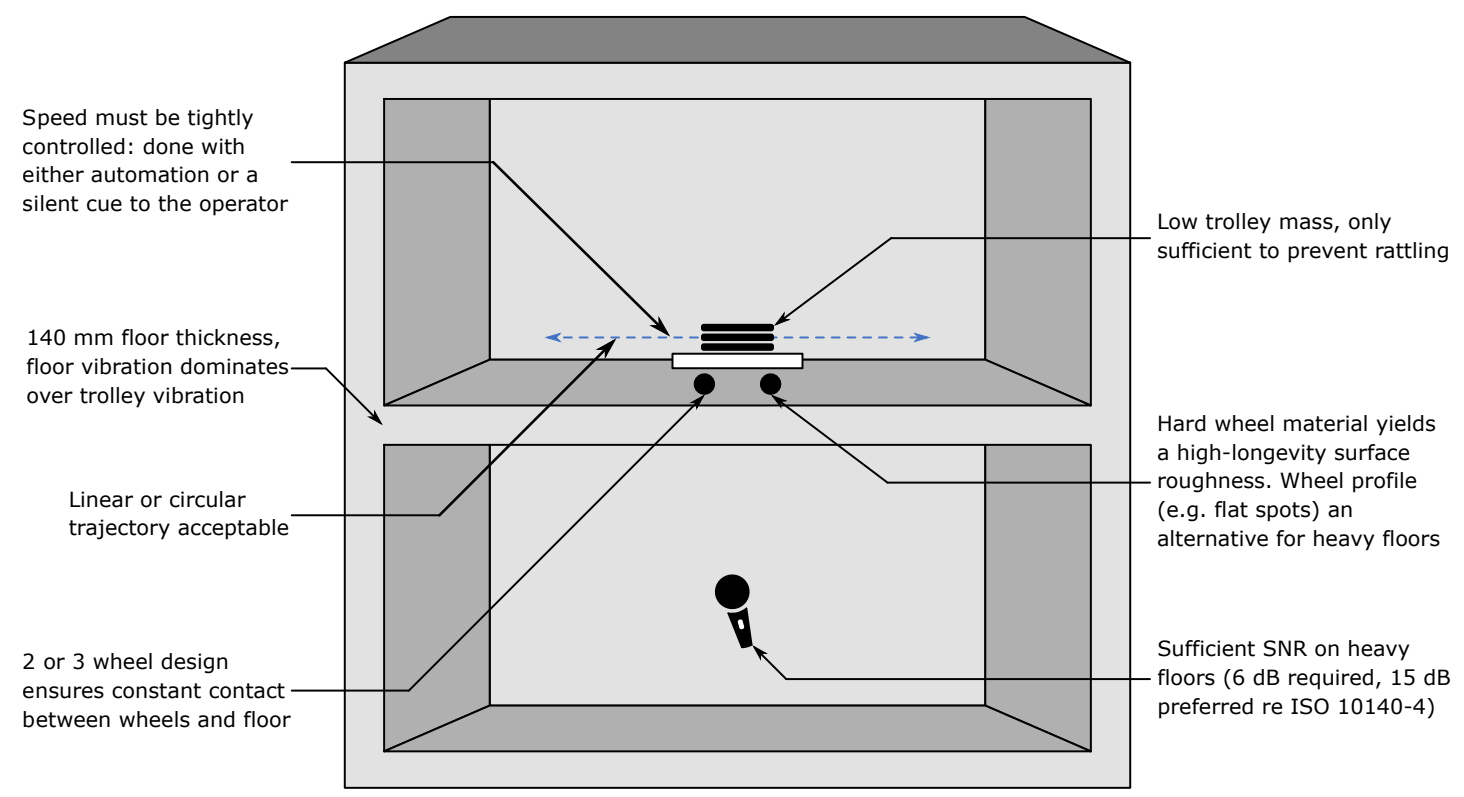

Figure 19: Specific considerations for a standard rolling device

While not strictly a design criterion for the rolling device itself per se, it is advisable that future lab tests be conducted on $140 \mathrm{~mm}$ floors, this being the classical thickness for concrete floors. This will also serve to reduce the influence of floor vibration on the measured results, as a heavier floor will have a lower mobility.

The rolling test devices used in this study were both manually pushed. This was found to yield results which were both repeatable (through the use of a silent cue to control trolley speed) and free from extraneous noise (the stepping of the operator did not contribute to the measured signal). However, automation should still be considered for a standard rolling device. There are designs which could possibly provide a consistent rolling trajectory without being overly complicated: such as a device which rolls in a circular trajectory around a fixed center point through the use of a rotating arm. This rotating arm may be driven either mechanically (e.g. via a coil spring) or electrically (e.g. via an electric motor). A schematic of such an example is 
shown in Figure 20. Here the length of the rotating arm, torque of the central motor, mass of the device, and mounting of the wheels need to be chosen to achieve the desired tangential speed and path radius without generating excess noise. An automated device has the potential to provide even greater repeatability in the results by removing human influence from the equation.

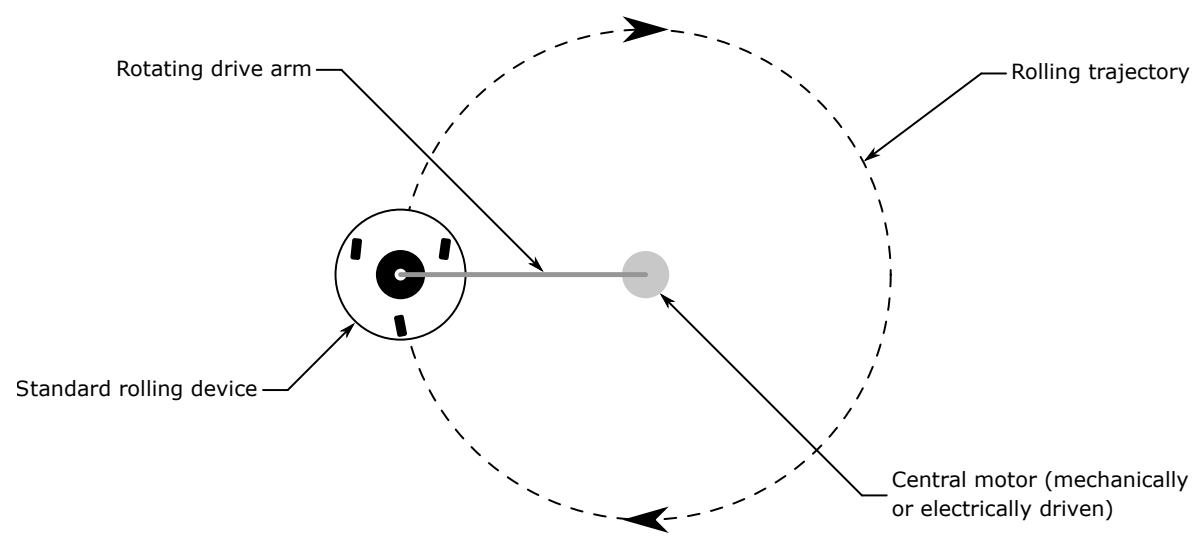

Figure 20: Schematic of a possible automated device setup

As with all engineered products, the device's design needs to be a balance of all the important factors, not simply those which dictate its acoustic performance. Ease of manufacturing, ease of use, cost, longevity, and other secondary factors will also play a role in the design process. Nevertheless, as the discussion on the development of a standard rolling machine evolves, the focus should always remain grounded in designing a rolling device which is as accurate and repeatable as possible.

\section{Conclusion}

This paper presents the proposal for a development of a standard rolling device. This work is linked to the recently accepted proposal to the European Committee for Standardization (CEN / TC 126 / WG 7) for a New Work Item: Measurement of rolling sound insulation. A series of rolling tests were conducted in order to determine the degree to which each measured characteristic has an effect on the generated rolling noise level. The trolley speed has a high influence on the radiated sound level, as does the presence (or not) of wheel flats. The wheel material has a large effect on the radiated sound level, while the added load and wheel spacing have a minor (though non-negligible) effect. The effect of the rolling trajectory and presence of a human operator are negligible.

The rolling test procedure used, combined with the modified measurement method for impact noise described in ISO 10140-3 [4], are adequate for generating reproducible results. Care must be taken to regulate the speed of the test trolley to the highest degree possible, but this is manageable through the use of a metronome or silent visual cue. Alternatively, an automated design may be used to further regulate the trolley speed and overall test procedure.

The results presented here may be used as guidance in developing a standard rolling noise device. Such a device should be designed to produce a "worst case scenario" in order to be usable on both light-weight and heavy-weight floors. While a three-wheeled device rolling in a circular trajectory would be easier to automate due to its self-stabilizing nature, a two-wheeled device pushed manually in a linear trajectory is also capable of producing a repeatable and reliable rolling sound signature. 


\section{Acknowledgments}

This work was done as part of Acoutect: an innovative training network composed of 5 academic and 7 non-academic participants. This consortium comprises various disciplines and sectors within building acoustics and beyond, promoting intersectoral, interdisciplinary and innovative training and mobility of the researchers within the project. This project has received funding from the European Union's Horizon 2020 research and innovation program under grant agreement No 721536. This work was also performed within the framework of the Labex CeLyA of Université de Lyon, operated by the French National Research Agency (ANR-10-LABX0060/ANR-11-IDEX-0007).

\section{References}

[1] ISO 10140-5:2010 - Acoustics - Laboratory Measurement of Sound Insulation of Building Elements - Part 5: Requirements for test facilities and equipment, 2010.

[2] Reiher H. Über den Schallschutz durch Baukonstruktionsteile (Sound Isolation by Building Construction Elements). Beiheft zue Gesundh-Ing 1932; 2(11): 2-28.

[3] Jarnerö K, Bard D and Simmons C. Vibration Performance of Apartment Buildings with Wooden Lightweight Frame-Work - Residents Survey and Field Measurements. AkuLite Report 6. Technical Report 2013:17, SP - Sveriges Tekniska Forskningsinstitut, SP Trä, 2013.

[4] ISO 10140-3:2010 - Acoustics - Laboratory Measurement of Sound Insulation of Building Elements - Part 3: Measurement of Impact Sound Insulation, 2010.

[5] BS EN 16205:2013+A1:2018 - Laboratory measurement of walking noise on floors, 2018.

[6] ISO 12354-4:2017 - Building acoustics - Estimation of acoustic performance of buildings from the performance of elements - Part 4: Transmission of indoor sound to the outside, 2017.

[7] Guigou-Carter C and Villot M. Study of Simulated Rainfall Noise on Multi-layered System. In Euronoise 2003. Naples, Italy.

[8] Guigou-Carter C and Villot M. Predicting the Acoustic Performance of Multilayered Structures Submitted to Structural Excitation. In DAGA 200\%. Stuttgart, Germany.

[9] Chéné JB, Guigou-Carter C, Foret R et al. Mesure et prédiction du bruit de pluie sur des systèmes multicouches. In 10ème Congrès Français d'Acoustique. Lyon, France.

[10] Chevillotte F, Bécot FX and Jaouen L. Rolling noise model for building acoustics purposes. In Euronoise 2015. Maastricht, the Netherlands.

[11] Chevillotte F. Rolling Noise Modeling in Buildings. In Acoustics '1\%. Boston, MA, USA.

[12] Edwards M, Chevillotte F, Jaouen L et al. Rolling Noise Modeling in Buildings. In 47th International Congress and Exposition on Noise Control Engineering (Internoise 2018): Impact of Noise Control Engineering. Chicago, IL USA. ISBN 978-1-5108-7303-2.

[13] ISO 10140-4:2010 - Acoustics - Laboratory Measurement of Sound Insulation of Building Elements - Part 4: Measurement Procedures and Requirements, 2010.

[14] ISO 10140-1:2016 - Acoustics - Laboratory Measurement of Sound Insulation of Building Elements - Part 1: Application Rules for Specific Products, 2016. 
[15] Chevillotte F, Bécot FX and Jaouen L. Analysis of Excitations from the Wavenumber Point of View. In NOVEM 2015. Dubrovnik, Croatia.

[16] ISO 10140-2:2010 - Acoustics - Laboratory Measurement of Sound Insulation of Building Elements - Part 2: Measurement of airborne sound insulation, 2010.

[17] ISO 717-1:2013 - Acoustics - Rating of sound insulation in buildings and of building elements - Part 1: Airborne sound insulation, 2013.

[18] Browning RC, Baker EA, Herron JA et al. Effects of obesity and sex on the energetic cost and preferred speed of walking. Journal of Applied Physiology 2006; 100(2): 390-398. DOI:10.1152/japplphysiol.00767.2005.

[19] ISO 4287:1997- Geometrical Product Specifications (GPS) - Surface texture: Profile method - Terms, definitions and surface texture parameters.

[20] Feder J. Fractals. Physics of Solids and Liquids, New York: Plenum Press, 1988. ISBN 978-0-306-42851-7.

[21] Hurst H. The Long-Term Storage Capacity of Reservoirs. Transactions of the American Society of Civil Engineers 1951; 116: 770-799.

[22] Aste T. Generalized Hurst Exponent. MATLAB Central File Exchange, https://www.mathworks.com/matlabcentral/fileexchange/30076-generalized-hurstexponent (2020, accessed 20 April 2020).

[23] Di Matteo T, Aste T and Dacorogna M. Scaling behaviors in differently developed markets. Physica A: Statistical Mechanics and its Applications 2003; 324(1-2): 183-188. DOI:10. 1016/S0378-4371(02)01996-9.

[24] Thompson D. Railway Noise and Vibration: Mechanisms, Modelling and Means of Control. Elsevier Science, 2009. ISBN 978-0-08-045147-3.

[25] Matteo TD, Aste T and Dacorogna MM. Long-term memories of developed and emerging markets: Using the scaling analysis to characterize their stage of development. Journal of Banking E Finance 2005; 29(4): 827-851. DOI:10.1016/j.jbankfin.2004.08.004.

[26] Di Matteo T. Multi-scaling in finance. Quantitative Finance 2007; 7(1): 21-36. DOI: $10.1080 / 14697680600969727$.

[27] ISO 7626-5:2019 - Mechanical vibration and shock - Experimental determination of mechanical mobility - Part 5: Measurements using impact excitation with an exciter which is not attached to the structure, 2019.

[28] Schultz TJ. Impact Noise Testing and Rating - 1980. Final NBS-GCR-80-249, Bolt Beranek and Newman Inc., Cambridge MA, USA, 1981.

[29] Edwards M, Diaz RG, Dallaji N et al. Recommendation for a Standard Rolling Noise Machine. arXiv:200812053 [physics] 2020; 2008.12053. 